\title{
A Histological Study of the Adrenal Gland in Aged Cows
}

\author{
By \\ Shoji Yamauchi \\ Department of Veterinary Anatomy, College of Agriculture, \\ University of Osaka Prefecture, Sakai, Osaka.
}

\section{Introduction}

The knowledge of the endocrine glands in aged animals seems necessary in the understanding of the relationship of endocrine glands to the whole organism. Most of our knowledge concerning the senile changes are based on the findings from laboratory animals. Meanwhile, reports concerning the ageing process of the endocrine glands of domestic animals are especially few. The present study is concerned with the histological changes in the adrenal glands from three aged cows.

The important facts in a histology of the bovine adrenal gland are that the adrenal cortex is characteristically lipid-poor and that the glomerulosa cells specifically contain abundant acidophil granules. It has been noted repeatedly in cattle that parallel conclusions similar to those in lipid-rich laboratory animals in respect to the histophysiology of the zona glomerulosa are hard to obtain.

The frequent age changes observed in the adrenal such as the proliferation of connective tissue, an appearance of pigment granules and a local degeneration have been reported in a various animal species (B l u me $\mathrm{thal}$, '59; J a y e, '53, '57; M e yers and $\mathrm{Ch}$ arip per, '56; P a y $\mathrm{n}$ e, '52). Working with rats, J a y $\mathrm{n}$ ('53) found a general decrease in cortical lipid content with increasing age. Meanwhile, $\mathrm{M}$ e y e $\mathrm{r}$ s and $\mathrm{C}$ h a $\mathrm{r}$ i p pe r ('56) reported an appearance of lipid material with an advancement of age in the hamster adrenal cortex. W e be r et al. ('56, '58, '59) postulated in their studies working with cattle that the zona glomerulosa is inactivated in those cases where oil red 0 stainable lipid droplets appear.

With regard to pigment granules, Jay ne ('57) found them in 
the inner cortical zones accompanying the severe cellular deterioration. A cellular degeneration with the accumulation of pigment in the cortical cells was also observed by $\mathrm{P}$ a y $\mathrm{n}$ e ('52) and he believed them to be of mitochondrial origin. Pigment in the cells of the adrenal cortex has generally been interpreted as a sign of ageing or degeneration. On the other hand, $\mathrm{N}$ ic a n der ('52) found pigment particles in the zona glomerulosa of normal cattle. In the present study interesting changes which have not hitherto been reported were found. In evaluating these changes, careful attention was paid to the age of the animal.

\section{Materials and Methods}

The adrenal glands from three aged cows $(28,21$ and 17 years old, respectively) were studied. All cows are of the Japanese Native Breed. The reproductive history of the individual is quite different being described in a previous paper by the author (Yama uch i, '63). The cow of Case I was autopsied at a university and the remainings were autopsied at local slaughterhouses, respectively. It was not possible to obtain complete information or history on some of the cows. Brief comments and adrenal weight of the animals are shown in a Table 1 .

Table 1. Notes on cows included in the study.

\begin{tabular}{|c|c|c|c|c|c|}
\hline \multirow{2}{*}{ Case No. } & \multirow{2}{*}{$\begin{array}{l}\text { Age in } \\
\text { years }\end{array}$} & \multirow{2}{*}{$\begin{array}{l}\text { Body } \\
\text { weight } \\
\text { kg. }\end{array}$} & \multicolumn{2}{|c|}{ Adrenal weight $\mathrm{g}$. } & \multirow{2}{*}{$\begin{array}{l}\text { Brief comments on } \\
\text { the animal }\end{array}$} \\
\hline & & & $\mathrm{R}$ & $\mathrm{L}$ & \\
\hline I (776) & 28 & 227 & 10.4 & 10.9 & $\begin{array}{l}\text { Worn out completely due } \\
\text { to the epulis of the } \\
\text { mandible when autopsied }\end{array}$ \\
\hline II (817) & 21 & 390 & 9 & 12 & $\begin{array}{l}\text { Healthy as measured by } \\
\text { visible examination } \\
\text { when autopsied }\end{array}$ \\
\hline III (862) & 17 & 244 & 8.6 & 10.3 & $\begin{array}{l}\text { Worn out due to the } \\
\text { unvisible reason }\end{array}$ \\
\hline
\end{tabular}

The adrenals were obtained as quickly as possible and cut into many 3-5 $\mathrm{mm}$ thick cross slices immediately after weighing of the organ. Two or three slices from each gland were placed in the fixatives. Fixatives used in a present study are 10\% formalin, Bou in's, Zenker-formalin, Carnoy's and Champy's. The adrenal of Case III was not obtained in a fresh state but a gland 
was fixed in $10 \%$ formalin. Therefore, refixation with some fixatives was applied.

After fixation, the tissues were processed through a standard paraffin technique and sections 5 micra thick were cut. The tissue slices fixed in $10 \%$ formalin was embedded in gelatin and cut on the freezing microtome in 10 micra sections. Staining methods used in this study are as follows, hematoxylin-eosin, azan (H e ide $\mathrm{n}$ h a inM a $110 \mathrm{ry}$ ), and PAS technique. Stainings for mitochondria such as iron hematoxylin and aniline acid-fuchsin are also employed. Those applied to frozen sections were Sudan IV, Sudan black B and a test. of Schultz for cholesterol.

Measurements of the width of the zona glomerulosa and the zona fasciculata together with the zona reticularis were made on each gland. Each datum listed in table 2 is the mean of three observations. For comparison, mean and range of the width of the each zone were measured from six normal young cows $(4,5$ and 6 years old, two each). As the transition from the zona fasciculata to the zona reticularis is not evident, the independent width of the inner cortical zones was difficult to measure.

The nuclear density in the outer and inner zona fasciculata was determined by counting the cortical cell nuclei in a unit area (0. $0441 \mathrm{~mm}^{2}$ ) of the field. Fibrotic areas as well as hyalinized areas were eliminated from the counting. Three countings were made in each case, and the mean value is listed in table 2. For comparison, the mean value of the cell nuclei with the standard deviation was obtained from the same normal young cows as described above. Preparations of the hematoxylin-eosin stain were used for both measurement and counting.

\section{Results}

\section{Measurement and Counting}

Table 2 lists the width of cortical zones and numbers of cell nuclei. The data expressed in table 2 indicate a little increase in width of the cortical zone with advancing age, but the degree is within a range of normal young cows.

Meanwhile, the average numbers of cell nuclei per unit area in both the outer and the inner zona fasciculata in aged cases indicate an overall decrease respectively. The most striking decrease in number is found in the inner fasciculata of Case $I$. In the 
Table 2. Measurement and count on the adrenal cortex of aged cows.

\begin{tabular}{|c|c|c|c|c|c|c|c|}
\hline \multirow{3}{*}{ Case No. } & \multirow{2}{*}{\multicolumn{3}{|c|}{ Average width of the cortex in $\mu$}} & \multicolumn{4}{|c|}{$\begin{array}{l}\text { Average number and ratio of } \\
\text { cell nuclei per unit area } \\
\text { of the } z \text {. fasciculata* }\end{array}$} \\
\hline & & & & \multicolumn{2}{|c|}{ Outer z. fasc. } & \multicolumn{2}{|c|}{ Inner $z$. fasc. } \\
\hline & z. glom. & z. fasc. $+z$ retic. & total cortex & nos. & ratio & nos. & ratio \\
\hline $\mathrm{I}$ & 198 & 2230 & 2428 & 103 & 43 & 107 & 42 \\
\hline III & 306 & 1674 & 1980 & 160 & 67 & 182 & 71 \\
\hline III & 372 & 1818 & 2190 & 175 & 73 & 172 & 67 \\
\hline $\begin{array}{l}\text { Young } \\
\text { cows** }\end{array}$ & $\begin{array}{c}261 \\
(126-378) \dagger+\end{array}$ & 1473 & $\mid \begin{array}{c}1734 \\
(1260-2232) \dagger\end{array}$ & $239 \pm 18 \dagger$ & 100 & $258 \pm 36 \dagger$ & 100 \\
\hline
\end{tabular}

Each datum is the mean of three observations.

* $0.21 \mathrm{~mm} \times 0.21 \mathrm{~mm}=0.0441$ square millimeter.

** Mean of six normal young cows is presented.

$\uparrow$ Mean \pm standard deviation.

t† Figure in parenthesis represents the range in width.

remaining two cases, the average numbers showed the level to be around $70 \%$ of those in young cows.

The average number of cell nuclei in an outer zona fasciculata from 3 aged cows is $146 \pm 31$, and that of the inner $z$. fasciculata is $154 \pm 33$, respectively. Analyses of variance for both outer and inner z. fasciculata between young and aged groups were undertaken by t-testing. Highly significant differences are presented between the two groups $(\mathrm{P}<0.01)$. In all cases, no remarkable difference was observed between the inner and outer $z$. fasciculatae in respect to the decrease in number of cell nuclei.

\section{Histology}

Zona glomerulosa. The stromal tissue is generally more prominent than in the young animals and the zone is separated into many groups of spherules by stromal tissue. At times, the normal arrangement of cells is so distorted in some areas that the semblance of the zonation seems to be that of the $z$. fasciculata.

Large pigment cells are abundantly found in a interspherular stromal tissue (Figs. 1 and 2). Pigment granules are brown to black in color and are unstained with all the methods employed. Apart from these pigment cells, there were present many parenchymatous cells containing pigment granules (Figs. 11-14). These pig- 
ment granules, yellow to brown in color, were observed to be closely associated with the cytoplasmic vacuole and frequently were found within vacuoles (Figs. 12 and 13). These pigment granules were also unstained with all the stains used. Vacuolar glomerulosa cells were seen more abundantly in the outer region than in the inner region. Pigment granules were arranged in such a pattern that a nucleus was difficult to observe (Fig. 13), and in an extreme case no nucleus with normal characteristics could be found (Fig. 14).

On the contrary in the normal gland, the $z$. glomerulosa at all age levels showed large amounts of sudanophil materials (Figs. 4 and 5). Lipid droplets were observed to correspond to the vacuoles described previously. The lipid accumulation in a glomerulosa zone was observed to be more intense than that in the remaining two cortical zones. Glomerulosa cells containing eosinophil granules are seen far less in number than the normal (Figs. 8 and 9). The intracellular distribution of granules was also less intense. In general, the vacuolar cells are seen to be poor in granules. A few cells adjacent to the trabecula penetrating into the cortex from the capsule exhibit less vacuolation and contain moderate amounts of eosinophil granules.

A more deteriorative feature of the glomerulosa zone was observed in one case (28 years old), where the glomerulosa zone was frequently interrupted by the downgrowth of the stromal tissue. In such areas, the capsular components are continuous with the intermediary connective tissue layer.

Intermediate zone. A thick fibrous layer is found in all glands at the junction of the $z$. glomerulosa and the $z$. fasciculata. The layer is composed exclusively from blood vessels and connective tissue fibers and runs parallel to the capsule (Fig. 3). A few parenchymatous cells are found scattered within a layer, though the cellular characteristics are quite different from those of the glomerulosa cell. The intermediate zone is very variable in width among the different specimens as well as within the different regions of the same specimen.

Zona fasciculata. Though an appearance of the $z$. fasciculata is variable among the different specimens, some common characteristics were observed. The degree of fat deposition in a zona fasciculata seems to somewhat less intense than in the z. glomerulosa and the lipid material is usually denser in the outer half of the zone than in the inner half (Fig. 4). In all cases the fasciculata lipid gave a negative result for cholesterol test. 
Many cells showing the evidence of atrophy are usually found in the outer half of the fasciculata. A majority of cells in suc. areas are ellipsoid to spindle shape and much smaller in size. Coincident with these changes, the nuclei are also spindle shaped and stain much darker (Fig. 9). A polyhedral cell having a vesicular nucleus as well as large amounts of cytoplasm was seldom found in all cases. As a result of the cellular atrophy appearing in an outer z. fasciculata, the cell cords become much narrower and concomitantly the sinusoids in that regions are much dilated (Figs. 9 and 10). As the shrinkage of the cell proceeds, the cell cords become narrower, hence the sinusoids appear more prominent than in the young cows.

In many regions of the outer $z$. fasciculata, especially those adjacent to the glomerulosa zone, many cells containing eosinophil granules which are quite similar to those of the glomerulosa cell can be found (Figs. 8 and 9). Granular fasciculata cells are also found in the inner half of the zone in lesser frequency. Intracellular granules were observed to be identical with those of the glomerulosa cell as far as the methods employed in this study.

In one specimen (Case III), the degenerative change was found in the zona fasciculata. The areas where the evidence of degeneration is shown are composed of fibrotic tissue and are usually sudanophobic (Fig. 4). Apart from the fibrotic degeneration, the hyalinization of the cortical tissue is commonly found in all cases. A hyalinized region is frequently seen in a deep cortex where the majority of cells are shrunken and the nuclei are pycnotic (Figs. 6 and 7$)$.

With respect to the adrenal medulla, no remarkable difference nor degenerative change was found in all specimens as far as the methods used in this study.

\section{Discussion}

In old fowls, P a y $\mathrm{n}$ e ('52) observed a reduction in size of the adrenal gland and he stated that the reduction is due in part to shrinkage of cells, but also in part, to degeneration of cells. In the present study, a reduction in weight of the adrenal was not noticed. The width of the total cortex as well as each cortical zone was greater in aged cows than those in young cows. A part of the increase in width of the cortical zone in aged cows seems probably due to a normal growth of the gland. S moll i ch ('58) stated that 
in the cow, the adrenal continues to increase in weight even after the end of the general body growth.

Hypertrophy seen in adrenal glands of multiparous cows was. considered to be due to the effects of stress such as lactation and pregnancy (B ell et al., '59). A long-term exhaustion especially at the high age level might be considered as a definite stresser. Although the widening of cortical zones is noticeable, it is accompanied by a decrease in cell number. Large values in width of the cortical zone in this study are probably not due to hypertrophy but within a normal range. With respect to the ageing aspects, the significant decrease in numbers of cell nuclei of the $z$. fasciculata is accepted as an evidence of the kind of atrophy which takes place in ageing. A similar significant decline in nuclear density in the late decades was reported in human adrenal cortex ( $\mathrm{M} \mathrm{a} \mathrm{K}$ in $\mathrm{n}$ on and $\mathrm{M}$ a c$\mathrm{K}$ i n n o n, '60). The decline in the nuclear density of the z. fasciculata in old cows suggests a reduction in fasciculata activity. This implies a fall in glucocorticoid production.

In normal bovine adrenal cortex, a Schultz test for cholesterol always showed negative result ( $\mathrm{N}$ i c a n de r, '52; W e be r et al., '50). A lipid accumulation in cortical zones of cattle has been reported in a series of paper by $\mathrm{W}$ e ber et al. ('56, '58, '59), and various. postulations have been drawn. In general, a lipid accumulation in the cattle adrenal cortex has been interpreted to represent an evidence of cellular inactivation. Adrenals of senile hamsters are reported to be stained well for sudanophilia and also for cholesterol (M e yers and Charipper, '56). An increase in sudanophilia in the later decades is considered as an evidence of the kind of atrophy which takes place in ageing ( $\mathrm{MacK}$ in $\mathrm{n}$ on and $\mathrm{M}$ a cKinnon,. '60). In contrast to the increase in lipid material just described above, the cytoplasmic lipids are observed to be either absent or considerably reduced in quantity in aged rats ( $\mathrm{J}$ a $\mathrm{ne}, 53$ ). In lipid-poor animals, the real significance of the appearance of cholesterol in the adrenal cortex at the advanced age or under experimental conditions is not precisely understood yet.

Pigment granules are often observed in cortical cells among various animals in relation to the senility and are well summarized in some articles (B o u r n e, '56; Carls o n, '52; $\mathrm{P}$ a y n e, '52). In most reports, the pigment granules are initially noticed in inner zones of the cortex and the accumulation has been observed to increase with age in mice (J a y $\mathrm{n} \theta$, '53 '57), rat (B l u menthal, '59), hamster (M e yers and $\mathrm{C}$ harip per, '56), and fowl (P a y $\mathrm{n}$. 
'52). Pigment accumulation is said to be one of the most pronounced and readily observable changes with ageing. Three processes in respect to an appearance of pigment granules are summarized in a paper by $\mathrm{Meyers}$ and $\mathrm{Charipper}$ ('56), and the presence of pigment in the cells is considered to probably be due to progressive difficulty of the cells to excrete poorly soluble products. It is noteworthy that no pigment granules were found at all in the deeper cortices of all aged cows. On the contrary, pigment granules in the z. glomerulosa have not been reported previously except by $\mathrm{N}$ i c a nde r ('52). The intracellular pigment granules arranged in such a pattern as a nucleus are one of the most striking features with respect to the senile changes. Pigment granules seemed to be of nuclear origin.

A regional disappearance of the z. glomerulosa would probably be due to the disappearance of nuclei from the cells of the region. A partial degeneration as well as marked fatty infiltration in the outer layer of the adrenal cortex is found in cows which appeared to have ketosis (S h a w et al., '48). An atrophy of the z. glomerulosa suggests a reduction in glomerular activity, which in turn implies a fall in aldosterone production.

An extensive appearance of granular cells found in the outer z. fasciculata of all aged cows seems very interesting in respect to the functional independence of the cortical zone. Cytoplasmic granules in the glomeruolosa cells have been observed exclusively in adrenals of cattle and sheep ( $\mathrm{N}$ i c a $\mathrm{n}$ de r, ' 52 ; W e be r et al., '50). Most investigators found granules were restricted to the $\mathrm{z}$. glomerulosa and interpreted this as an indication of a cellular activity (S c h u lt z and M e yers, '58a and b ; W e be r et al., '50; Y a m au chi, '61). An appearance of granular cells in the z. fasciculata reported in this paper seems to be one of the characteristics compensating the decline in glomerulosal function. Apart from these cells, a few granular cells were also found in the vicinity adjacent to the trabecula penetrating into the cortex.

In connection with the cell replacement in the adrenal cortex, the renewal of glomerulosa cells from indifferent capsular cells through a series of cellular morphogenesis and a downgrowth of cell cords during the growth of the adrenal cortex have been confirmed (Elias, '48; Gruen $\mathrm{W}$ a ld and $\mathrm{K}$ on ikov, '44; Stokoe, ' 60 ; $\mathrm{Z}$ w e m e $\mathrm{r}$ et al., ' 38 ). In the bovine adrenal cortex, $\mathrm{N}$ i c a n d e r ('52) described an intermediary zone between the z. glomerulosa and the $\mathrm{z}$. fasciculata and he postulated that the zone, at least partly 
consists of atrophied cell groups originally constituting the innermost layers of the z. glomerulosa. In aged cows, a dense fibrous layer poor in parenchymatous cell was observed between the $\mathrm{z}$. glomerulosa and the z. fasciculata. The layer seems so thick that one can not speculate the downgrowth of cortical cells. This interruption would result in a striking decrease of cell nuclei in the $\mathrm{z}$. fasciculata.

It should be noted that two cows were not healthy at the time of autopsy. A consideration that the adrenal glands had probably been affected by such a factor as long-termed exhaustion seems to be necessary. in evaluating the changes presented here.

\section{Summary}

Adrenal glands from three aged cows (Japanese Native Cattle) were studied histologically. Animals were 28,21 and 17 years old, respectively.

A remarkable reduction in nuclei density of the outer $z$. fasciculata as well as the inner $z$. fasciculata was noted. The data presented here showed highly significant differences between the young and aged cows.

The z. glomerulosa was most severely affected among the cortical zones in respect to the advancing age. Those enumerated in the $\mathrm{z}$. glomerulosa are, lipid deposition and pigment cells in both the stromal and the parenchymatous tissue. The pigment granules of parenchymatous cells seem to probably be the degenerative material of cell nuclei.

A regional disappearance of the z. glomerulosa was considered as one of the striking change. An appearance of a dense fibrous layer between the $\mathrm{z}$. glomerulosa and the $\mathrm{z}$. fasciculata was discussed from the viewpoint of the downgrowth of cortical cells. Those changes described here would probably imply a reduction in activity of this zone.

The fasciculata cells were much reduced not only in number but also in size. Lipid deposition and dilated sinusoids were also remarkable. Those changes enumerated in the z. fasciculata would probably imply a reduction in activity of this zone. Fibrotic or hyalinized areas were frequently found within the $\mathrm{z}$. fasciculata.

An extensive appearance of granular cells in the outer $z$. fasciculata was one of the most striking changes. Characteristics of the cytoplasmic granules were quite similar as those in glomerulosa 
cells as far as methods used and the functional significance of these granular cells was discussed.

\section{Literature cited}

B e 11, T. T. and A.F. W e be r 1259. A comparative study of lipid accumulation in the adrenal glands of mature nonpregnant dairy heifers, nonpregnant lactating dairy cows, and pregnant lactating dairy cows. Am. J. Vet. Res., 20, 53-60.

B l u m e $\mathrm{nth}$ a l, H.T. 1959. Ageing process in the endocrine glands of various strains of normal mice:Relationship of hypophyseal activity to ageing changes in other endocrine glands. J. Gerontol., 10, 253-267.

B o u rne, G.H. 1956. Ageing from a biological and cellular point of view, in "Modern Trends in Geriatrics" ed. by W. Hobs o n. Butterworth, London.

C ar 1 s o n, A.J. 1952. The thyroid, pancreatic islets, parathyroids, adrenals, thymus and pituitary, in "Cowdry's Problems of Ageing" ed. by A.I. Lansing. Willi a ms \& Wilkins, Baltimore.

Elia s, H. 1948. Growth of the adrenal cortex in domesticated ungulata. Am. J. Vet. Res., 9, 173-189.

Grue n wa ld, P. and W. M. K on ik ov 1944. Cell replacement and its relation to the zona glomerulosa in the adrenal cortex of mammals. Anat. Rec., 89, 1-21.

J a y n e, E.P. 1953. Cytology of the adrenal gland of the rat at different ages. Anat. Rec., 115, 459-484.

- 1957. Histochemical and degenerative changes in the adrenal cortex of the rat with age. J. Gerontol., 12, 2-8.

Mackinnon, P.C.B. and I.L. Mackinnon 1960. Morphologic features of the human suprarenal cortex in men aged 20-86 years. J. Anat., 94, 183-191.

Me yers, M.W. and H. A. Ch a ripper 1956. A histological and cytological study of the adrenal gland of the golden hamster (Cricetus auratus) in relation to age. Anat. Rec., 124, 1-25.

$\mathrm{Ni}$ c a n der, L. 1952. Histological and histochemical studies on the adrenal cortex of domestic and laboratory animals. Acta anat., 14 (Suppl. 16), 1-88.

P a y n e, F. 1952. Cytological changes in the cells of the pituitary, thyroids, adrenals, and sex glands of ageing fowl, in "Cowdry's Problems of Ageing" ed. by A.I. L a n sing. Williams \& Wilkins, Baltimore.

Schultz, R.L. and R.K. Meyers 1958a. Cytochemical characterization of the granules in zona glomerulosa of the bovine adrenal gland. J. Cell. and Comp. Physiol., 52, 1-12.

1958b. Biological activity of fractions obtained by differential centrifugation of the bovine adrenal cortex. J. Biophys. and Biochem. Cytol., 4, 23-28.

$\mathrm{Shaw}$, J.C., B.C. Hatziolos and V.P. Saarinen 1948. A biochemical and histo-pathological study of ketosis in dairy cattle. J. Dairy Sci., 31, 667.

S mollich, A. 1958. Gestalt, Topographie, Masse und Gewichts-verhältnisse der Nebenniere des Rindes. Anat. Anz., 105, 205-221.

Stok o e, W.M. 1960. Corticoadrenal morphogenesis in the sheep. Wien. Tierärztl. Monatschr. Festschrift Prof. Sch re i be r. 394-410.

W e ber, A.F., S.H. McNutt and B.B. Morgan 1950. Structure and arrangement of zona glomerulosa cells in the bovine adrenal. J. Morph., 83, 393-416.

We ber, A.F., J.T. Bell and A.F. Sellers 1958. Studies of the bovine adrenal 
gland. II. The histological and cytochemical effects of the administration of 1 , 1 dichloro-2, 2-bis (P-chlorophenyl) ethane on the adrenal cortices of dairy calves. Am. J. Vet. Res., 19, 51-57.

Weber, A.F., W.B. Pritchard and A.F. Sellers 1956. Studies of the bovine adrenal gland. I. The production of lipid accumulation and other histological and cytological changes in the zonae glomerulosae of calves. Am. J. Vet. Res., $17,402-409$.

Y a m a u chi, S. 1961. The structure of the zona glomerulosa in the bovine adrenal gland. Bull. Univ. Osaka Pref., Ser. B., 11, 37-46.

1963. A histological study on ovaries of aged cows. (In Japanese with English summary). Jap. J. Vet. Sci., 25, 315-322.

Zwemer, R.L., R.M. Wotton and M.G. Norkus 1938. A study of corticoadrenal cells. Anat. Rec., 72, 249-263.

\section{Explanation of Figures}

Fig. 1. Case III. Pigment cells are seen in the z. glomerulosa and also in a capsule. Degenerative fasciculata is noted in a lower right portion of the photo. H.E stain, $\times 100$.

Fig. 2. Case II. Stromal pigment cells are evident. Granules contained in parenchymatous cells are mitochondria. Iron-hematoxylin stain, $\times 400$.

Fig. 3. Case II. A fibrous layer is found between the two cortical zones. Azan stain, $\times 100$.

Fig. 4. Case III. A heavy deposition of the lipid material within a cortex. A fibrotic region is sudanophobic. Sudan IV stain, $\times 10$.

Fig. 5. Case II. A lipid staining of the $z$. glomerulosa. Lipid granules with various sizes are abundantly seen. Sudan IV stain, $\times 400$.

Fig. 6. Case III. The intermediary zone is being hyalinized. Glomerulosa cells are generally poor in cytoplasm. Azan stain, $\times 10$.

Fig. 7. Case III. Deep cortex and the medulla. A hyalinization of the parenchyme is noticed. Azan stain, $\times 100$.

Fig. 8. Case III. A border region of the outer two cortical zones. Some fasciculata cells contain cytoplasmic granules whereas glomerulosa cells lack granules and poor in cytoplasm. Granules are stained red. $H \cdot E$ stain, $\times 400$.

Fig. 9. Case I. The outer fasciculata zone adjacent to the z. glomerulosa. Granules contained in many cells retain an orange-yellow color. Cellular shrinkage as well as the dilation of sinusoids are noticed. Azan stain, $\times 400$.

Fig. 10. Case I. A deep $z$. fasciculata where the cellular shrinkage is recognizable. H. E stain, $\times 400$.

Fig. 11. Case II. A border region of the outer cortical zones. Intracellular pigment granules are frequent. Granules are brown in color. PAS counterstained with hematoxylin, $\times 400$.

Fig. 12. Case I. Glomerulosa zone. M, mitochondria; P, pigment granules. Pigment granules are brown. Aniline acid-fuchsin stain, $\times 900$.

Fig. 13. Case I. Glomerulosa zone. P, pigment granules. Intravacuolar pigment granules are also noted in the spherule. PAS counterstaind with hematoxylin, $\times 900$.

Fig. 14. Case I. Glomerulosa zone. No nucleus is found within a spherule (upper), but pigment granules are shown. Compare with the neighboring spherule. PAS counterstained with hematoxylin, $\times 400$. 
Plate I
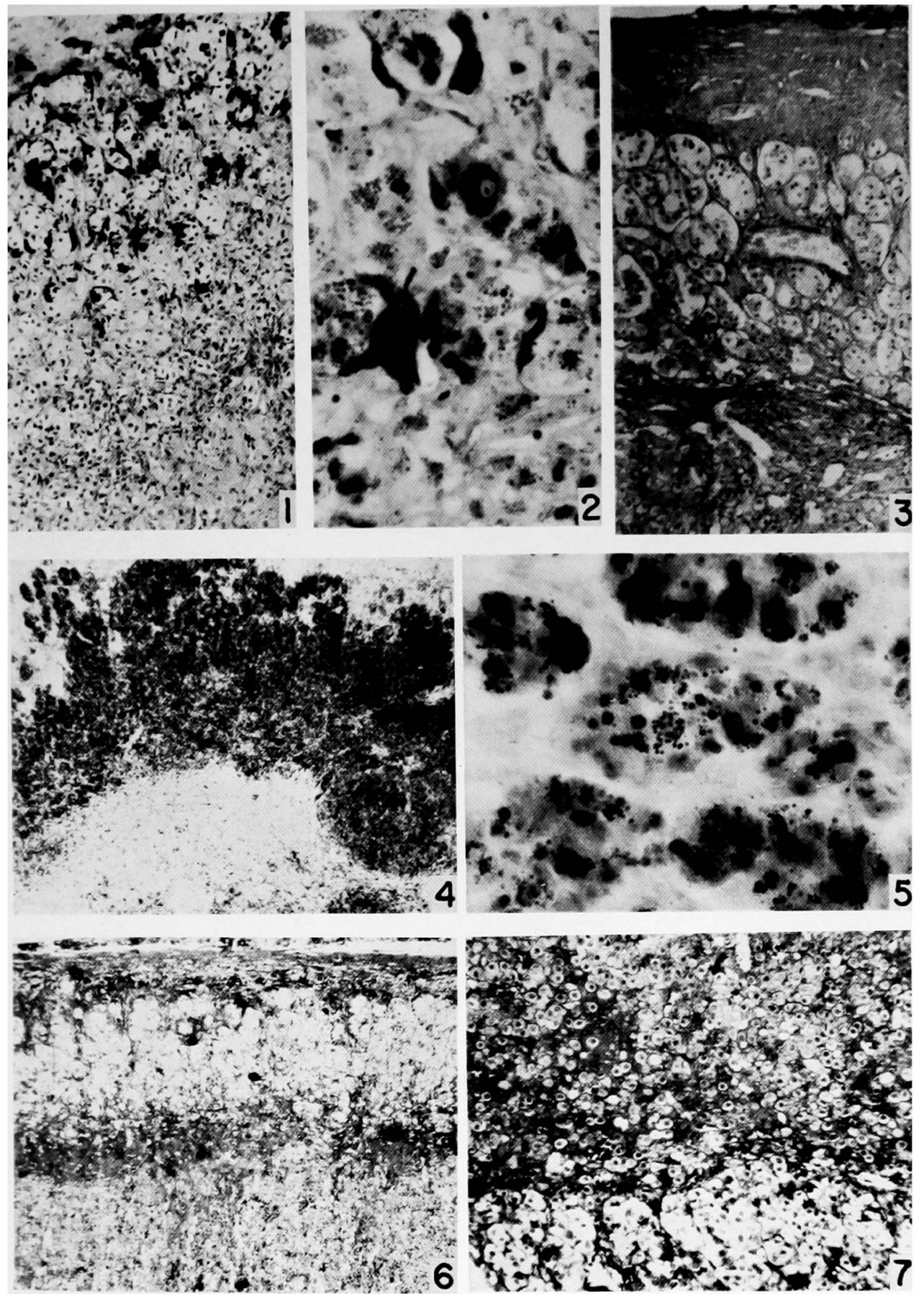

S. Yamauchi 
Plate II
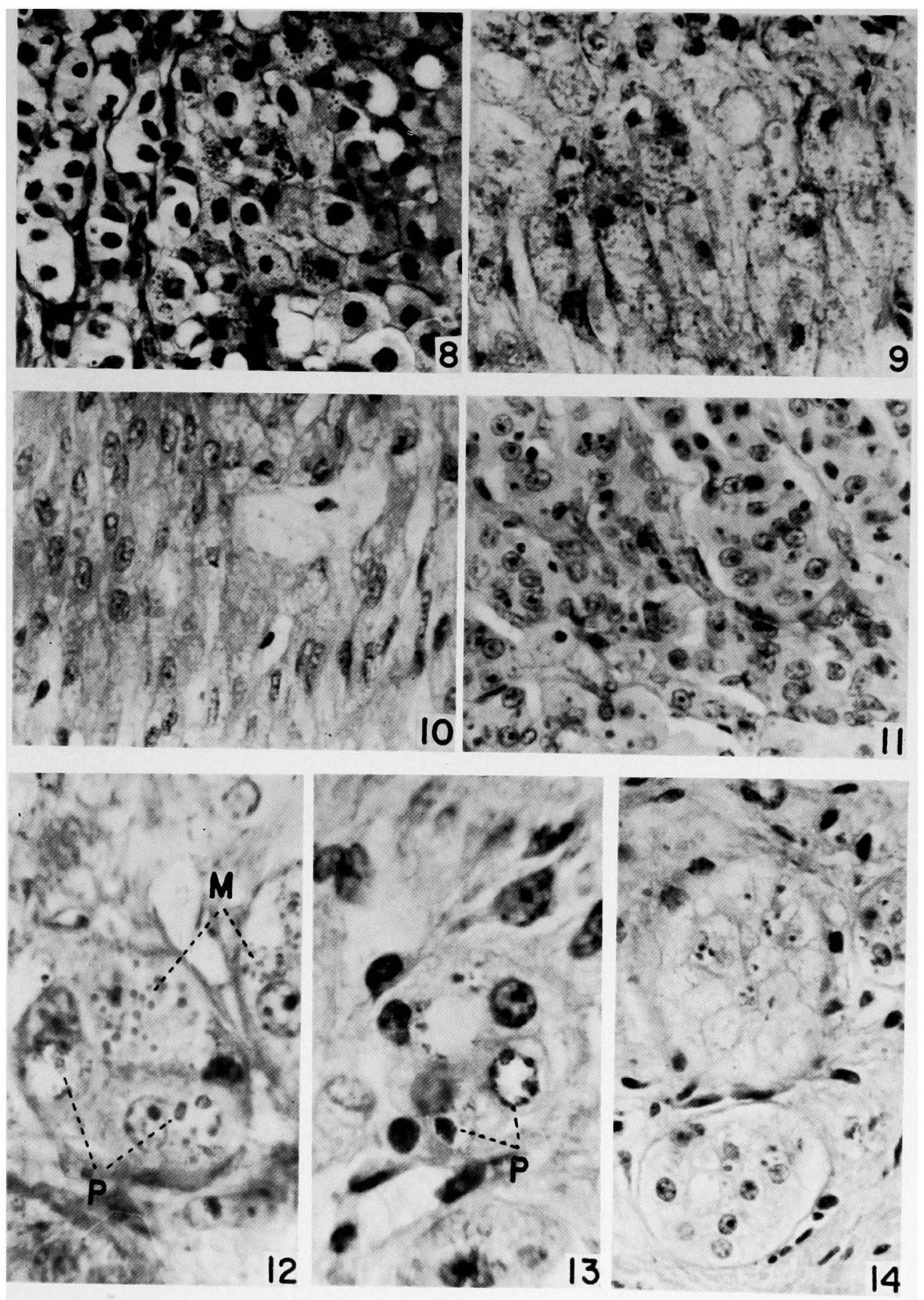

S. Yamauchi 